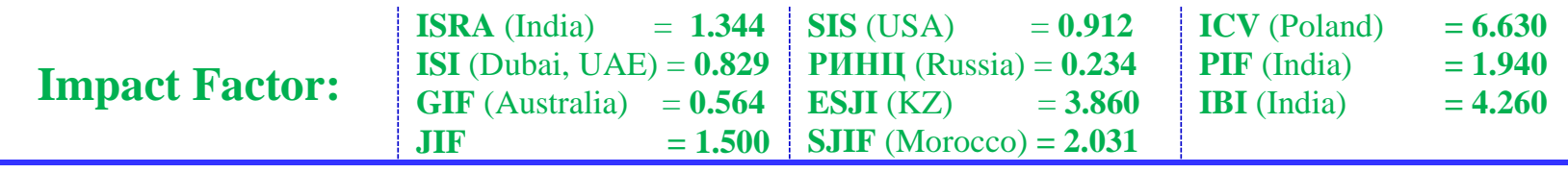

\section{SOI: $\underline{1.1 / \mathrm{TAS}}$ DOI: $10.15863 / \mathrm{TAS}$ International Scientific Journal Theoretical \& Applied Science}

p-ISSN: 2308-4944 (print) e-ISSN: 2409-0085 (online)

Year: 2017 Issue: $05 \quad$ Volume: 49

Published: $25.05 .2017 \quad$ http://T-Science.org

SECTION 23. Agriculture. Agronomy. The technique.
Asan Ospanov

Doctor of Technical Science, Professor Scientific Research Institute Mechanization and Electrification of Agriculture

Makhamedkali Kenzhekhojayev Candidate of Technical Sciences, Associate professor Head of the department «Technology of food products, processing industries and biotechnology»

M.Kh. Dulaty Taraz State University, Kazakhstan k-mahamed@mail.ru

Galymzhan Yussupov

Master of technical science

Lecturer of the department «Technology of food products, processing industries and biotechnology» M.Kh. Dulaty Taraz State University, Kazakhstan yussupov.g@gmail.com

\title{
THEORY OF MINERAL IMPURITIES SEPARATION PROCESS ON THE SCREW RING SURFACE
}

Abstract: This paper considers the method of separation process of of mineral impurities on the screw ring surface. The research of granular materials on separation processes without net rough supporting surfaces allowed acknowledging the expedient improvement of cleaning grain of mineral admixtures in annular corrugated working bodies with radial racing.

Key words: separation process, mineral impurities, grain.

Language: English

Citation: Ospanov A, Kenzhekhojayev M, Yussupov G (2017) THEORY OF MINERAL IMPURITIES SEPARATION PROCESS ON THE SCREW RING SURFACE. ISJ Theoretical \& Applied Science, 05 (49): 8691.

Soi: http://s-o-i.org/1.1/TAS-05-49-16 Doi: croskef https://dx.doi.org/10.15863/TAS.2017.05.49.16

\section{UDC 631.362.3}

\section{Introduction}

A special place among the weeds of grain took the hard separable mineral impurities, which by their size and aerodynamic properties are close to grains. These include: pebbles, coarse sand, broken glass, pieces of metal and other things.

For its technological indicators the best and recognized worldwide are the Vibration-pneumatic stone pickers - a prototype of a grain cleaning machine MTSat-100. In the Republic of Kazakhstan and CIS countries, the machine-analogues of the Russian manufacture R3-TUC-100 are mainly used. The experience of operation of Vibration-pneumatic stone pickers, their main drawbacks are: low productivity and high energy consumption[1].

A great contribution to the study of the processes of separation of grain and products of its processing, including the process of clearing grain of mineral impurities, was made many scholars: V.P. Goryachkin, K.K., V.N. Andrianov, V.M. Aniskin,
Bochkovskij A.V., Cecinovskij V.M. Panchenko, Alexander ulyanov, R.N. Volik, G.E. Listopad, I.I. Blekhman, V. Hajnman, V. Gortinskij, Nikolai Avdeyev, A.N. Ahuravlev, Tm zaika, V.A., Kubyshev A.I. Lyubimov, A. Vasiliev, B.A. Bucko, R.N. Kasymov, D.J., a.b. Abdeli Ospanov, M. J. Erkebaev and many others.

The research of granular materials on separation processes without net rough supporting surfaces allowed acknowledging the expedient improvement of cleaning grain of mineral admixtures in annular corrugated working bodies with radial racing. Preference is given to the separating bodies in the form of a horizontal circular channel with the screw plot engaged in rotational oscillation around a vertical central axis. To separate the mineral impurities from grains of mainstream culture, you need to create the conditions of their transportation on screw surfaces through races[2,3]. 


\begin{tabular}{|c|c|c|c|c|c|c|}
\hline Impact Factor: & $\begin{array}{l}\text { ISRA (India) } \\
\text { ISI (Dubai, UAE } \\
\text { GIF (Australia) } \\
\text { JIF }\end{array}$ & $\begin{array}{l}=1.344 \\
=0.829 \\
=0.564 \\
=1.500\end{array}$ & $\begin{array}{l}\text { SIS (USA) } \\
\text { PИНЦ (Russia) } \\
\text { ESJI (KZ) } \\
\text { SJIF (Morocco) }\end{array}$ & $\begin{array}{l}=0.912 \\
=0.234 \\
=3.860 \\
=\mathbf{2 . 0 3 1}\end{array}$ & $\begin{array}{l}\text { ICV (Poland) } \\
\text { PIF (India) } \\
\text { IBI (India) }\end{array}$ & $\begin{array}{l}=6.630 \\
=1.940 \\
=4.260\end{array}$ \\
\hline
\end{tabular}

\section{Materials and methods}

The proposed device for clearing grain of mineral impurities (Figure 1) is an annular channel 1, limited external and internal concentric 4 and 3 circular Rapids, riffles with radial 5 on its surface. The perimeter ring channel 1 from the outer threshold of 3 are 6 race. Horizontal circular channel 1 moves to block tray 7 angle $\alpha$ formed from screw exterior threshold and races 2 . When this screw 7 tray race is tilted towards the central axis of the annular channel 1 on an angle $\beta$. outdoor 3 threshold Height greater than the height of the internal ring 4 threshold. Radial grooves 5 and 6 form a race between a gap, providing unimpeded movement of grain and mineral particles.

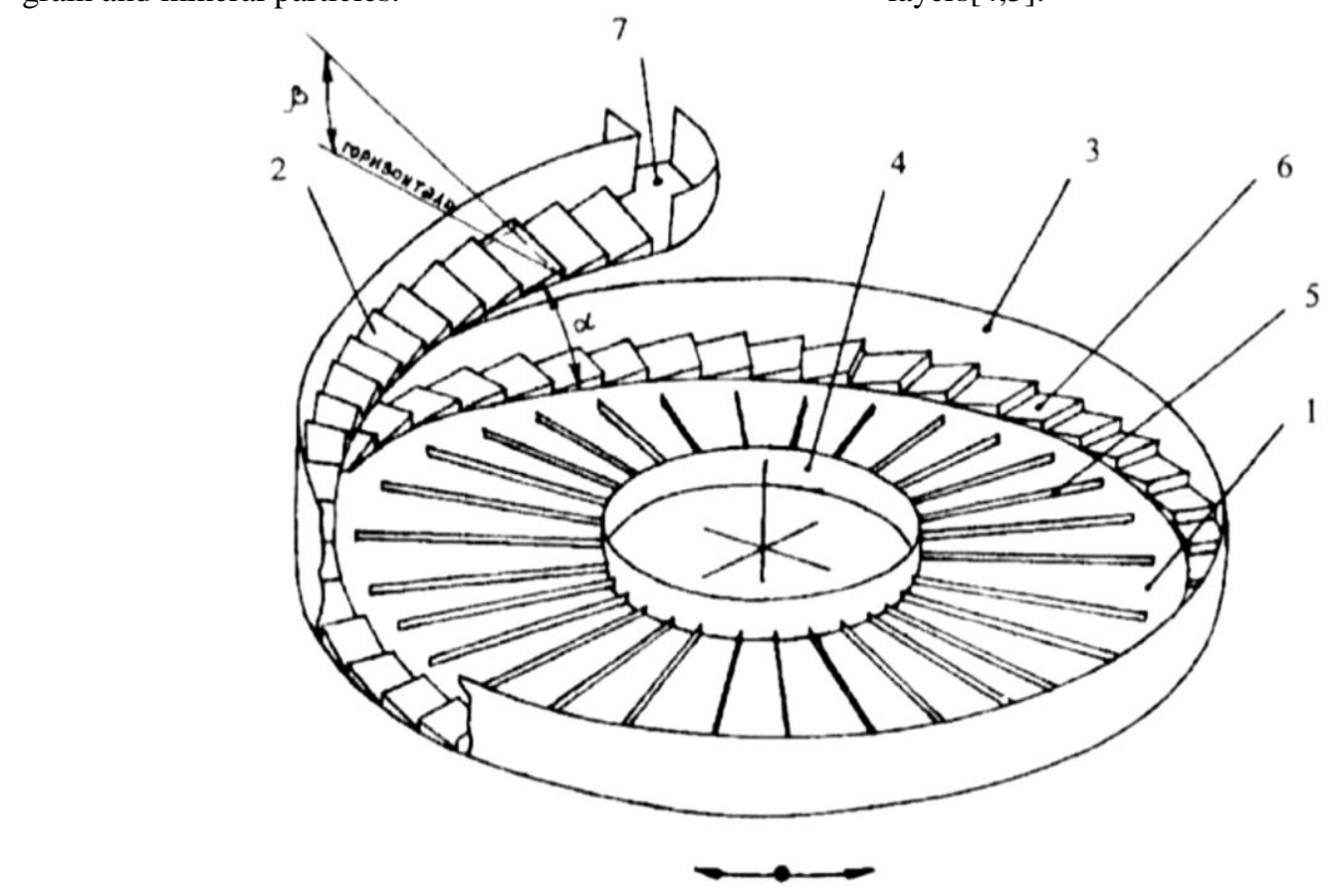

Figure 1-Scheme of the device for the cleaning of grain from mineral impurities
The device works as follows. Operation commits rotational oscillations relative to the vertical central axis. The original grain mixture that contains grains of mainstream culture and mineral amixtures, continuously served on top of the average radius of the ring Canal 1. In the beginning, the grain mixture fills the ring channel 1 with simultaneous withdrawal of block tray 7 by 2 races. Effects of radial riffles 5 when rotational vibrations of the working body, requires intensive self-sorting separate of grain mixtures. While across the width of the ring Canal into lower layers are intensively dive mineral impurities, filling the space between the radial riffles 5 , displacing the main crop beans from the lower layers[4,5].
Mineral impurities by means of radial riffles 5 under centrifugal forces reach the entire perimeter ring races 6 channel through which move to block tray 7. Reaching screw tray, mineral admixtures and some grains of mainstream culture will be picked up by inclined toward the Center screw tray 2 races. Because particles of mineral admixtures have greater mass and friction on the surface of the races than grains of mainstream culture with less weight and round shape, contributing to their rolling on the surface of the races, they become sustainable grip races, moving on a sloping surface 2 races screw to the exit tray. Grain and mainstream culture, less resistant to coupling with a surface of the races 2 will be tumbling down towards the races to the surface slope cultivated separate grain mixtures. The main grain crops, especially in the upper layers of the treated separate grain mixtures will be poured through the internal ring 4 threshold.

Considered are the relative motion of the particles in the form of a material point on screw tray committing rotational oscillations around the central axis of the o-o (Figure 2) on the harmonic law[6]

$\varphi=\varphi_{0} \sin \omega t ; \dot{\varphi}=\varphi_{0} \cos \omega t ; \ddot{\varphi}=\varphi_{0} \omega^{2} \sin \omega t$,

where $\varphi, \dot{\varphi}, \ddot{\varphi}$ and are $\varphi_{0}$, respectively, the value of angular displacement, speed and acceleration of the work of the authority, as well as its current angular movement.

Screw the angle $\alpha$ tray tilted towards the central axis of oscillation-about with an angle $\beta$. it will be noted that mineral particles, heavier due to centrifugal force of inertia must be clamped to the 


\begin{tabular}{l|lrl|l|ll} 
& ISRA (India) & $=\mathbf{1 . 3 4 4}$ & SIS (USA) & $=\mathbf{0 . 9 1 2}$ & ICV (Poland) & $=\mathbf{6 . 6 3 0}$ \\
Impact Factor: & ISI (Dubai, UAE) $=\mathbf{0 . 8 2 9}$ & PUHL (Russia) $=\mathbf{0 . 2 3 4}$ & PIF (India) & $=\mathbf{1 . 9 4 0}$ \\
& GIF (Australia) & $\mathbf{0 . 5 6 4}$ & ESJI (KZ) & $=3.860$ & IBI (India) & $=\mathbf{4 . 2 6 0}$
\end{tabular}

outer ring, and less heavy and light particles (grain main crop) because of the round shape will slide into the side of the tilt screw races tray. Believe that screw tray is formed from a variety of races in increments and height of serving pieces. Take the length of the race is equal to the total displacement of the particle.

Consider the equation equilibrium of particles on the surface of the screw plot when subjected to the following forces:

$P_{u}^{\tau}=-m \ddot{\varphi} R=m R \varphi_{o} \omega^{2} \sin \omega t$ and

$P_{u}^{n}=-m \dot{\varphi}^{2} R=m R \varphi_{o}{ }^{2} \omega^{2} \cos ^{2} \omega t$-respectively the tangential and normal forces of inertia in a figurative movement;
$F_{1}=F_{2}=f N$-friction of particles on the surface of the screw tray; where $f$ is the coefficient of friction, $N$-normal reaction; $G=m g$ - the force of gravity.

Differential equations of relative motion of particles in a coordinate system $X Y Z$ will look like this:

$$
\begin{aligned}
& m \ddot{x}=P_{u}^{\tau} \cos \alpha-F_{2}-G \cos \beta \sin \alpha ; \\
& m \ddot{y}=P_{u}^{n} \cos \beta-F_{1}-G \cos \alpha \sin \beta ; \\
& m \ddot{z}=N-P_{n}^{\tau} \sin \alpha-P_{u}^{n} \sin \beta-G \cos \alpha \cos \beta
\end{aligned}
$$

Since the motion of a particle on the surface of the screw of the Pan should be no heaving ( $\ddot{z}=0$ and $z=$ const $)$ of (2) can be identified

$$
N=m R \varphi_{o} \omega^{2} \sin \omega t \sin \alpha+m R \varphi_{o}^{2} \omega^{2} \cos ^{2} \omega t \sin \beta-m g \cos \alpha \cos \beta
$$

(3) write the relative particle acceleration on axis $\mathrm{X}$

$$
\ddot{x}=f R \varphi_{o}^{2} \omega^{2} \sin \beta\left[\sin ^{2} \omega t+\frac{(\cos \alpha-f \sin \alpha)}{f \varphi_{o} \sin \beta} \sin \omega t-\frac{g c t g \beta}{f R \varphi_{o}^{2} \omega^{2}}(f \cos \alpha-\sin \alpha)\right]
$$

We introduce the notation

$$
A=f R \varphi_{o}^{2} \omega^{2} \sin \beta ; B=\frac{(\cos \alpha-f \sin \alpha)}{f \varphi_{o} \sin \beta} ; Z=\frac{g \operatorname{ctg} \beta}{f R \varphi_{o}^{2} \omega^{2}}(f \cos \alpha-\sin \alpha)
$$

Here is the equation (4) to mean

$$
\ddot{x}=A\left[\sin ^{2} \omega t+B \sin \omega t-Z\right],
$$

Have in mind that

Then equation (6) takes the form

$$
\delta=\omega t ; \ddot{x} \frac{d \dot{x}}{d t}=\frac{d \dot{x}}{d \delta} \omega
$$




\begin{tabular}{|c|c|c|c|c|c|c|}
\hline Impact Factor: & $\begin{array}{l}\text { ISRA (India) } \\
\text { ISI (Dubai, UAE } \\
\text { GIF (Australia) } \\
\text { JIF }\end{array}$ & $\begin{array}{r}=1.344 \\
=0.829 \\
=0.564 \\
=1.500\end{array}$ & $\begin{array}{l}\text { SIS (USA) } \\
\text { PИHЦ (Russia) } \\
\text { ESJI (KZ) } \\
\text { SJIF (Morocco) }\end{array}$ & $\begin{array}{l}=0.912 \\
=0.234 \\
=3.860 \\
=\mathbf{2 . 0 3 1}\end{array}$ & $\begin{array}{l}\text { ICV (Poland) } \\
\text { PIF (India) } \\
\text { IBI (India) }\end{array}$ & $\begin{array}{l}=6.630 \\
=1.940 \\
=4.260\end{array}$ \\
\hline
\end{tabular}

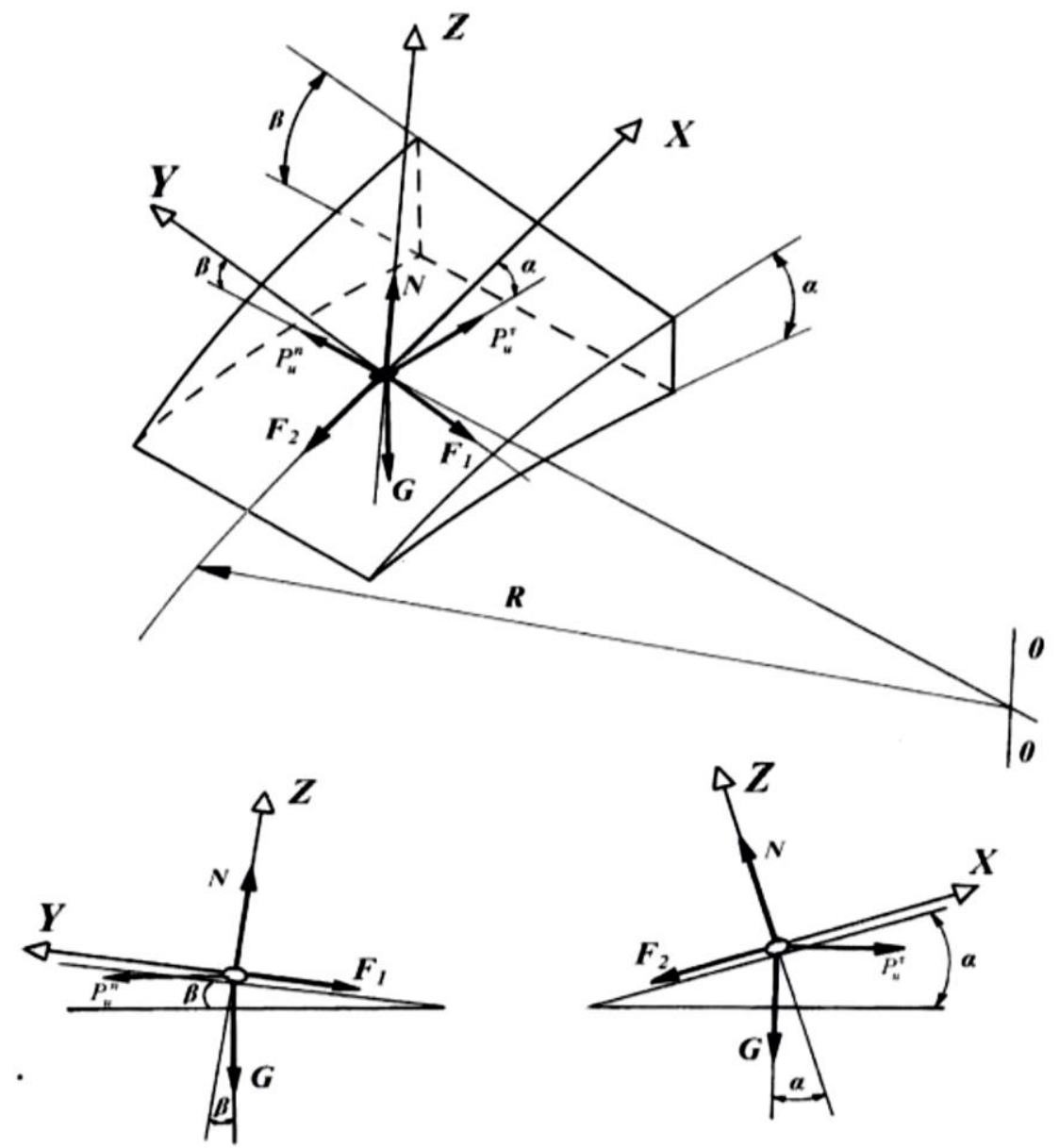

Figure 2 - Diagram of the forces acting model particle.

$$
\ddot{x}=\frac{A}{\omega}\left[\left(\frac{1}{2}-Z\right) \delta-\frac{1}{4} \sin 2 \delta-B \cos \delta\right]
$$

Having in mind that $\dot{x}=\frac{d x}{d t}=\omega \frac{d x}{d \delta}$, after integration and transformation we get moving particles along the axis of $X$

$$
x=\frac{A}{\omega^{2}}\left[\left(\frac{1}{2}-Z\right) \frac{\delta^{2}}{2}+\frac{\cos 2 \delta}{8}-B \sin \delta\right]
$$

Average relative speed of a particle along the axis of $x$ is determined by equation

$$
V_{(x)}=\left(x_{+}+x_{-}\right) \frac{\omega}{2 \pi},
$$

Where $x_{+}, x_{-}$-accordingly, particles move along and against the axis $x$ for the period of the oscillations of the ring Canal.

From equations (2) and (3) have

$$
\ddot{y}=R \varphi_{o}^{2} \omega^{2}(f \sin \beta-\cos \beta)\left[\sin ^{2} \omega t-\frac{\sin \alpha}{f \varphi_{o}(f \sin \beta-\cos \beta)} \sin \omega t-\right.
$$

We introduce the notation

$$
\begin{aligned}
& K=R \varphi_{o}^{2} \omega^{2}(f \sin \beta-\cos \beta) \\
& M=\frac{\sin \alpha}{f \varphi_{o}(f \sin \beta-\cos \beta)}
\end{aligned}
$$$$
N=\left[\frac{(f \sin \beta+\cos \beta)-\frac{g \cos \alpha}{R \varphi_{o}^{2} \omega^{2}}(f G s \beta-\sin \beta)}{f \sin \beta-\cos \beta}\right]
$$

Equation (10) quote to mean

$$
\ddot{y}=K\left\lfloor\sin ^{2} \omega t-M \sin \omega t-N\right\rfloor
$$

If $\omega t=\delta ; \ddot{y}=\frac{d \dot{y}}{d t}=\frac{d \dot{y}}{d \delta} \omega$, takes the form

$$
\dot{y}=\frac{K}{\omega}\left[\left(\frac{1}{2}-N\right) \delta-\frac{1}{4} \sin 2 \delta+M \cos \delta\right] \text {. }
$$

It is known that $\dot{y}=\frac{d y}{d t}=\omega \frac{d y}{d \delta}$, after integration and transformations have moving particles along the axis Y

$$
y=\frac{K}{\omega^{2}}\left[\left(\frac{1}{2}-N\right) \frac{\delta^{2}}{2}+\frac{\cos 2 \delta}{8}-M \sin \delta\right] d \delta
$$




\begin{tabular}{|c|c|c|c|c|c|c|}
\hline Impact Factor: & $\begin{array}{l}\text { ISRA (India) } \\
\text { ISI (Dubai, UAE } \\
\text { GIF (Australia) } \\
\text { JIF }\end{array}$ & $\begin{array}{l}=1.344 \\
=0.829 \\
=0.564 \\
=1.500\end{array}$ & $\begin{array}{l}\text { SIS (USA) } \\
\text { PИНЦ (Russia) } \\
\text { ESJI (KZ) } \\
\text { SJIF (Morocco) }\end{array}$ & $\begin{array}{l}=0.912 \\
=0.234 \\
=3.860 \\
=\mathbf{2 . 0 3 1}\end{array}$ & $\begin{array}{l}\text { ICV (Poland) } \\
\text { PIF (India) } \\
\text { IBI (India) }\end{array}$ & $\begin{array}{l}=6.630 \\
=1.940 \\
=4.260\end{array}$ \\
\hline
\end{tabular}

Average relative speed of a particle along an axis $Y$ is determined by equation

$$
V_{(Y)}=\left(y_{+}+y_{-}\right) \frac{\omega}{2 \pi},
$$

Where $y_{+}$and $y_{-}$are, respectively, to move the particles along and against the axis $Y$ for the period of the oscillations of the ring Canal.

Conducting calculation equations (9) and (15) on the MAINFRAME by tabulating the relative particle velocity dependences, in our case the mineral impurities with friction on steel surface $f_{3 . n .}=0,47$ and grains primary crops (wheat) with friction $f_{3 . n .}=0,28$, as shown in figures 3 and 4 .

From the charts (Figure 3) shows that at constant values of the angular amplitude $\varphi_{o}=12^{\circ}$ and frequency $\quad \omega=12,9 c^{-1} \quad\left(n=120 \mathrm{~min}^{-1}\right)$ fluctuations in the work of the authority, as well as at the races angle to the axis of the fluctuations $\beta=0$, with an increase in angle screw tray reduced relative velocities of particles from the axis of oscillation of the ring Canal. In doing so, as the angle of the lifting screw tray difference between velocities of mineral admixtures and wheat grains increases[7,8].

With increasing angle of helical section from 0 to 25 degrees radial relative velocity of particles is reduced in mineral impurities from 0.98 up to 1.5 $\mathrm{m} / \mathrm{sec}$, and wheat grains from 1.39 to $0.49 \mathrm{~m} / \mathrm{s}$ Respectively, the difference in velocities increased from 0.32 to $0.9 \mathrm{~m} / \mathrm{s}$. This means that as the angle of the lifting screw tray due to the forces of gravity and friction forces mineral impurities are beginning to lag behind the main crop beans. An increase in angle screw plot more than 20 degrees difference leads to an increase in the relative velocities of the particles, so for rational angle $\alpha$ can take 20 degrees[9].

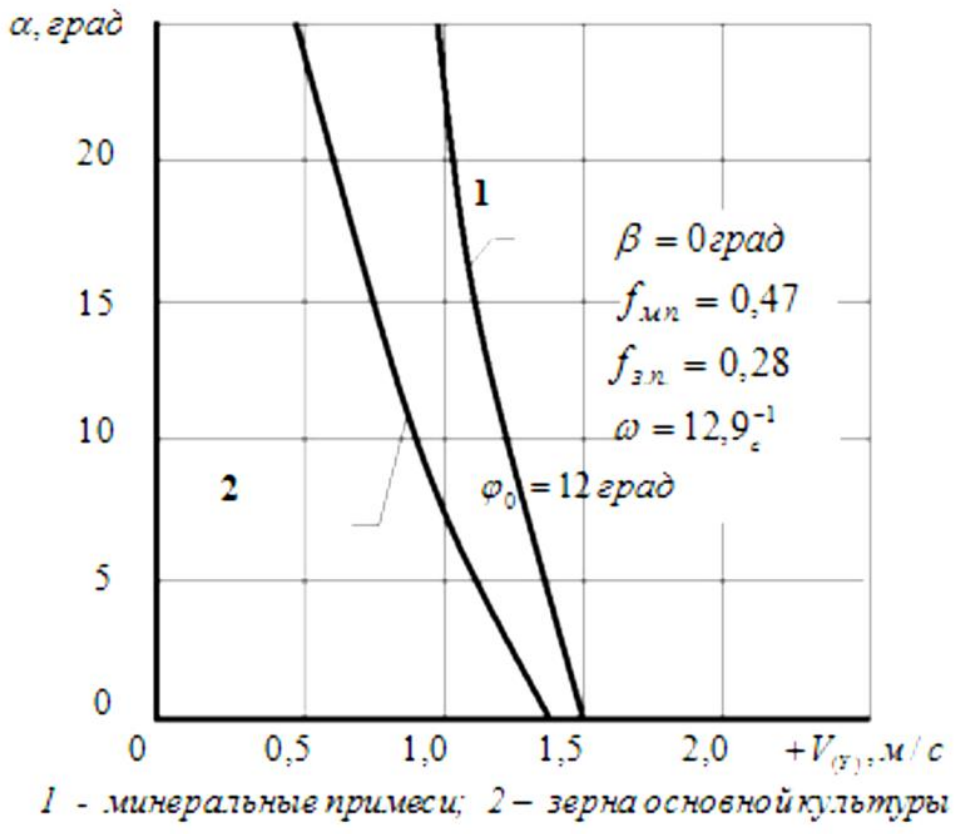

Figure 3-angle Dependence of helical tray from relative velocity components separate grain mixtures on axis $\mathbf{Y}$.

As you can see from Figure 4, when $\alpha=20^{\circ}$ mineral impurities accept relative quiet in angle screw the tray to the axis of the oscillations of the $\beta=8$ degrees, and wheat grains in $\beta=5,2$ degrees. Radially opposite movement of partial components at races angle to the axis of oscillation, equal $\beta=6$ degrees, where mineral impurities will be transported in an axis $\mathrm{Y}$ to the outer circular doorstep with speed $+V_{(Y)}=0,22 \mathrm{~m} / \mathrm{s}$, and wheat in the negative direction of axis $\mathrm{Y}$ to the Centre of oscillation speeds of $-V_{(Y)}=0,34 \operatorname{MPs}[10,11]$. 


\begin{tabular}{|c|c|c|c|c|c|c|}
\hline Impact Factor: & $\begin{array}{l}\text { ISRA (India) } \\
\text { ISI (Dubai, UAE } \\
\text { GIF (Australia) } \\
\text { JIF }\end{array}$ & $\begin{array}{l}=1.344 \\
=0.829 \\
=0.564 \\
=1.500\end{array}$ & $\begin{array}{l}\text { SIS (USA) } \\
\text { PИНЦ (Russia) } \\
\text { ESJI (KZ) } \\
\text { SJIF (Morocco) }\end{array}$ & $\begin{array}{l}=0.912 \\
=0.234 \\
=\mathbf{3 . 8 6 0} \\
=\mathbf{2 . 0 3 1}\end{array}$ & $\begin{array}{l}\text { ICV (Poland) } \\
\text { PIF (India) } \\
\text { IBI (India) }\end{array}$ & $\begin{array}{l}=6.630 \\
=1.940 \\
=4.260\end{array}$ \\
\hline
\end{tabular}

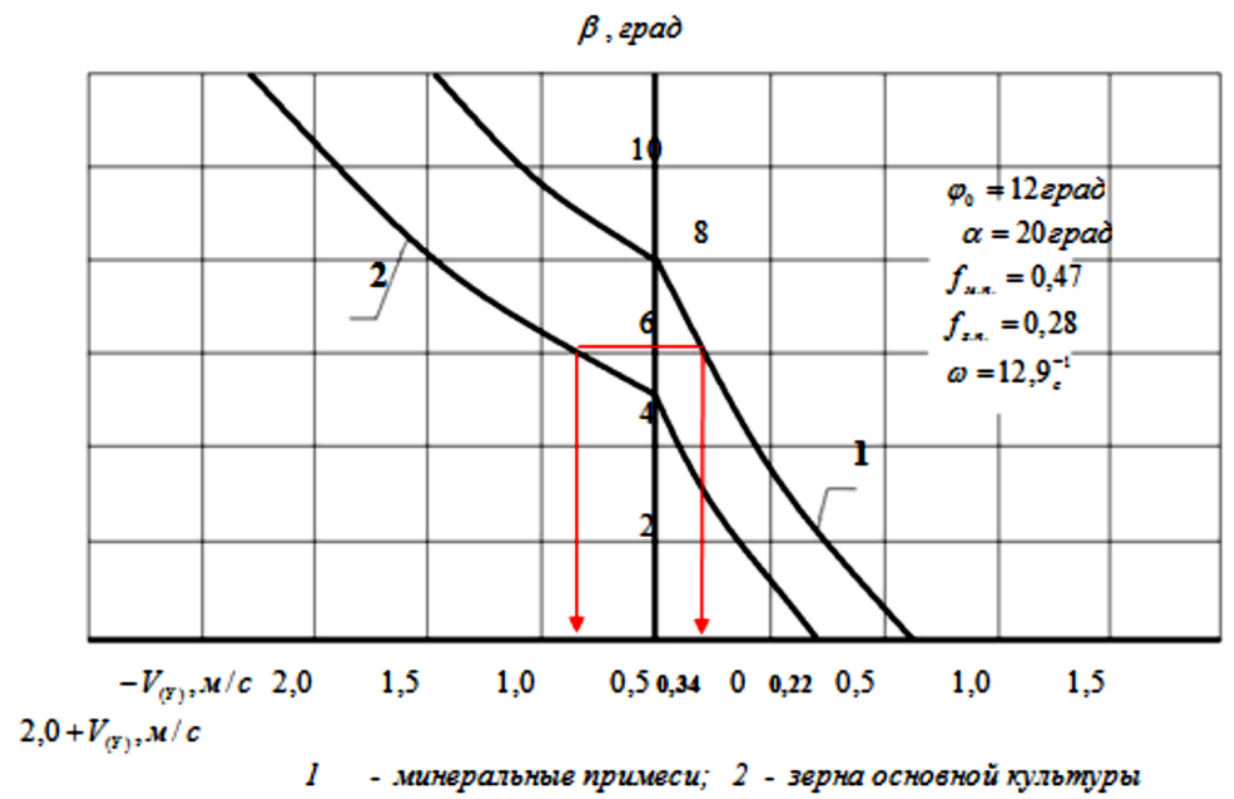

Figure 4 - The dependence of tilt angle to the axis of races fluctuations of relative velocity components separate grain mixtures along an axis $Y$.

\section{Conclusion}

Thus, the pattern is set vibrating movement of particles of mineral admixture and grains of mainstream culture by screw conveyor in radial- opposite directions depending on their physicalmechanical properties and kinematic parameters of a working body to determine design parameters of screw tray and races.

\section{References:}

1. Iztaev AI, Naleev ON (2011) Osimdik sharuashylygynyn onimderin ondeu jane saktau. - Almaty.

2. Kozhuhovskii IE (1960) Issledovanie raboty ploskih reshet. // Trudy VIM. -M..

3. Gortinskii VV, Demskii AB, Boriskin MA (1980) Processy separirovaniy na zernopererabatyvaushih predpriytiyh. - M.: Kolos.

4. Ospanov AB, Sadybaev AK, Kenzhehodjaev MD (1997) Dandi dakyldardy suryptauwy separatordyn terbelmeli massasyn tengeruwi kondyrgy // Zharshy. Almaty, Bastau. №6.

5. Ospanov AB, Baimuratov DS (2012) Dongelek bederli tasbolgishte dandi dakyldardy mineraldy kospalardan tazartu procesinin eksperimental'dy zertteu natizheleri "VII Dulaty okulary" Halykaralyk gylymi-praktikalyk konferenciysynyn materilaldary, $100-103$ p. 2021 sauir 2012. III tom, Taraz.

6. Kozhuhovskii IE, Pavlovskii GT (1968) Mehanizaciy ochistki i sushki zerna. - M.: Kolos.

7. Faibushevich TZ (1966) Separaciy zerna na vibracionnyh reshetkah. -Vestnik sel'skohozyistvennoi nauki.

8. Ptushkina GV (1970) Sovremennye zernoochistitel'nye mashiny. -M.: CNIITEIlegpishemash.

9. (1978) Obrabotka zerna na hlebopriemnyh predpriytiyh Kazakhstana. -Almaty: Kainar.

10. (1991) Spravochnik po zernovym kul'turam / Pod redakciei I.M. Karasuka. - Kiev.: Urozhai.

11. Butkovskii VA (1996) Podgotovka zerna k pererabotke // Hleboprodukty. 


\begin{tabular}{l|lr|ll|ll} 
& ISRA (India) & $\mathbf{1 . 3 4 4}$ & SIS (USA) & $=\mathbf{0 . 9 1 2}$ & ICV (Poland) & $=\mathbf{6 . 6 3 0}$ \\
Impact Factor: & ISI (Dubai, UAE) $=\mathbf{0 . 8 2 9}$ & PUHЦ (Russia) & $=\mathbf{0 . 2 3 4}$ & PIF (India) & $=\mathbf{1 . 9 4 0}$ \\
& GIF (Australia) & $=\mathbf{0 . 5 6 4}$ & ESJI (KZ) & $=\mathbf{3 . 8 6 0}$ & IBI (India) & $=\mathbf{4 . 2 6 0}$ \\
& JIF & $\mathbf{1 . 5 0 0}$ & SJIF (Morocco) & $\mathbf{2 . 0 3 1}$ & & \\
\hline
\end{tabular}

